\title{
The psychiatrist as expert witness. Part 2: criminal cases and the Royal College of Psychiatrists' guidance ${ }^{\dagger}$
}

\author{
Keith J. B. Rix
}

\begin{abstract}
Psychiatrists reporting in criminal cases in England and Wales are now governed by the Criminal Procedure Rules on expert evidence and these will require changes to the format and content of psychiatrists' reports in criminal proceedings. This article sets out the new rules and also draws attention to additional requirements made by the Court of Appeal and, when instructed by the police or the Crown Prosecution Service, by the Crown Prosecution Service. It also draws attention to the report of the Scoping Group on Court Work of the Royal College of Psychiatrists.
\end{abstract}

This is the second of two articles by Keith Rix that consider the role of the psychiatrist as expert witness. The first article, on general principles and civil cases, appeared in the previous issue of APT (Rix, 2008).

On 6 November 2006 new rules came into force concerning expert evidence in the criminal courts of England and Wales. They take the form of Part 33 of the Criminal Procedure Rules 2005 (Department of Constitutional Affairs, 2006). They have been consciously modelled on Part 35 of the Civil Procedure Rules (Rix, 2000) and are based in part on guidance on expert evidence established in the Ikarian Reefer case (Rix, 1999). The rules are set out in Box 1.

\section{The Criminal Procedure Rules}

The rules do not refer explicitly to psychiatric evidence but in Rule 33.1, where the meaning of 'expert' is set out, specific reference is made to the evidence required to determine fitness to plead and for the purpose of sentencing. These rules will apply to all cases in which psychiatrists prepare or give expert evidence for the purpose of criminal proceedings in England and Wales.

In setting out the expert's duty (Rule 33.2(1)) it is made explicit that the expert must help the court to achieve the overriding objective, which is that

${ }^{\dagger}$ For commentaries on this article see pp. 115-118 and 119-121, this issue. criminal cases be dealt with justly. This is achieved by the expert giving 'objective, unbiased opinion on matters within his expertise'.

\section{Form and content of reports}

Psychiatrists who are used to prepare reports for civil proceedings will quickly adjust to the new rules. Psychiatrists who have little or no experience of preparing reports and giving evidence in civil cases, however, will probably have to make changes to their practice and in particular to the form and content of their reports.

Reports in criminal cases will need to include a biographical section in which the psychiatrist sets out not only his ${ }^{1}$ qualifications but also his relevant experience and accreditation (Rule 33.3(1)(a)). It is usual to set out these matters in brief in the first paragraph of the report and to provide a more detailed biography as an appendix. The court needs to know what qualifies the psychiatrist as an expert in the particular case.

Where the psychiatrist relies on any particular literature, this must be mentioned (Rule 33.3(1)(b)). References can be set out in footnotes and the court will be best assisted if papers or chapters quoted are copied in full and incorporated in an appendix.

1. Throughout, my use of masculine pronouns mirrors their use in the Criminal Procedure Rules.

Keith Rix is a consultant forensic psychiatrist practising independently in London, Norfolk and West Yorkshire, and at Cygnet Hospital, Wyke. He is based in West Yorkshire (The Grange, 92 Whitcliffe Road, Cleckheaton BD19 3DR, UK. Email: drrix@the-grange.org.uk). He is a Fellow of the Expert Witness Institute and a Member of the Academy of Experts. He sits as a Chairman of the General Medical Council's Fitness to Practise Panel. 


\section{Box 1 The Criminal Procedure Rules. Part 33: Expert evidence (Department of Constitutional Affairs,} 2006) (C) Crown Copyright)

\section{Reference to expert}

33.1

A reference to an 'expert' in this Part is a reference to a person who is required to give or prepare expert evidence for the purpose of criminal proceedings, including evidence required to determine fitness to plead or for the purpose of sentencing.

\section{Expert's duty to the court}

33.2

(1) An expert must help the court to achieve the overriding objective by giving objective, unbiased opinion on matters within his expertise.

(2) This duty overrides any obligation to the person from whom he receives instructions or by whom he is paid.

(3) This duty includes an obligation to inform all parties and the court if the expert's opinion changes from that contained in a report served as evidence or given in a statement under Part 24.

\section{Content of expert's report}

33.3

(1) An expert's report must:

(a) give details of the expert's qualifications, relevant experience and accreditation;

(b) give details of any literature or other information which the expert has relied on in making the report;

(c) contain a statement setting out the substance of all facts given to the expert which are material to the opinions expressed in the report or upon which those opinions are based;

(d) make clear which of the facts stated in the report are within the expert's own knowledge;

(e) say who carried out any examination, measurement, test or experiment which the expert has used for the report and:

(i) give the qualifications, relevant experience and accreditation of that person;

(ii) say whether or not the examination, measurement, test or experiment was carried out under the expert's supervision;

(iii) summarise the findings on which the expert relies.

(f) where there is a range of opinion on the matters dealt with in the report:

(i) summarise the range of opinion, and

(ii) give reasons for his own opinion;

(g) if the expert is not able to give his opinion without qualification, state the qualification;

(h) contain a summary of the conclusions reached;

(i) contain a statement that the expert understands his duty to the court, and has complied and will continue to comply with that duty;

(j) contain the same declaration of truth as a witness statement.
(2) Only paragraphs (i) and (j) of rule 33.3(1) apply to a summary by an expert of his conclusions served in advance of that expert's report.

\section{Expert to be informed of service of report}

33.4

A party who serves on another party or on the court a report by an expert must at once inform that expert.

\section{Pre-hearing discussion of expert evidence}

33.5

(1) This rule applies where more than one party wants to introduce expert evidence.

(2) The court may direct the experts to -

(a) discuss the expert issues in the proceedings; and

(b) prepare a statement for the court of the matters on which they agree and disagree, giving their reasons.

(3) Except for that statement the content of that discussion must not be referred to without the court's permission.

\section{Failure to comply with directions}

33.6

A party may not introduce expert evidence without the court's permission if the expert has not complied with a direction under rule 33.5.

Court's power to direct that evidence is to be given by a single joint expert

33.7

(1) Where more than one defendant wants to introduce expert evidence on an issue at trial, the court may direct that the evidence on that issue is to be given by one expert only.

(2) Where the co-defendants cannot agree who should be the expert, the court may -

(a) select the expert from a list prepared or identified by them; or

(b) direct that the expert be selected in such other manner as the court may direct.

\section{Instructions to a single joint expert}

33.8

(1) Where the court gives a direction under rule 33.7 for a single joint expert to be used, each of the codefendants may give instructions to the expert.

(2) When a co-defendant gives instructions to the expert he must, at the same time, send a copy of the instructions to the other co-defendant(s).

(3) The court may give directions about -

(a) the payment of the expert's fees and expenses; and

(b) any inspection, examination or experiments which the expert wishes to carry out.

(4) The court may, before an expert is instructed, limit the amount that can be paid by way of fees and expenses to the expert.

(5) Unless the court otherwise directs, the instructing co-defendants are jointly and severally liable for the payment of the expert's fees and expenses. 
The requirement that the substance of the facts given to the psychiatrist that are material to the opinions expressed in the report be stated (Rule 33.3(1)(c)) can usually be satisfied by setting out the factual contents of the letter of instruction in a section entitled 'Summary of case on instruction and substance of all material instructions' and placed towards the beginning of the report.

In almost all psychiatric reports prepared for criminal proceedings, the only facts that are within the psychiatrist's own knowledge are the findings on mental state examination. Rule 33.3(1)(d) can be easily and explicitly satisfied by a footnote to the heading 'Psychiatric (mental state) examination', or an opening sentence in this section, stating 'These are the only facts within my own knowledge'.

If the psychiatrist refers to the results, for example, of psychological testing or neuroimaging, the report will need to include details of the person who carried out the tests (Rule 33.3(1)(e)).

It will not usually be enough for the psychiatrist to give his own opinion. Where there is a range of opinion, the psychiatrist will have to indicate what that range is and give reasons for his own opinion (Rule 33.3.(1)(f)). It might be helpful to consider what divergent but reasonable opinions would be given if the case were to be presented at a psychiatric case conference.

If the psychiatrist cannot give a definitive opinion, for example through inability to access certain records or because the outcome of treatment is awaited, this must be made clear (Rule 33.3.(1)(g)).

In the past, few psychiatric reports in criminal cases included a summary of the conclusions reached. This is now mandatory (Rule 33.3(1)(h)). Opinion is divided as to whether this summary is most helpfully placed at the beginning of the report (just after the 'Summary of the case on instruction') or at the end.

Another new requirement is that there must be a statement that the expert understands his duty, has complied with it and will continue to do so (Rule 33.3(1)(i)). Psychiatrists can use a full experts' declaration such as that shown in Box 2 or, if they prefer a shorter declaration, can use the first paragraph on its own.

\section{Box 2 Expert's declaration}

\section{I, JOHN MONRO, DECLARE THAT:}

1 I understand that my primary duty in written reports and giving evidence is to give objective, unbiased opinion on matters within my expertise in order to help the court to achieve its overriding objective. I understand that this duty overrides any obligation to the person from whom I have received instructions or by whom I am paid. I have complied and will continue to comply with that duty.

2 I have no conflict of interest of any kind, other than any which I have disclosed in this report, and I do not consider that any interest which I have disclosed affects my suitability as an expert witness on any issue about which I have expressed an opinion.

3 I have set out in my report what I understand from those instructing me to be the questions in respect of which my opinion as an expert is required.

4 I have endeavoured in my report and in my opinions to be accurate and to have covered all relevant issues concerning the matters stated which I have been asked to address. Absence of any comment in this report does not indicate that I have no opinion on a matter. I may not have been asked to deal with it. All of the matters on which I have expressed an opinion lie within my field of expertise.

5 I have endeavoured to include in my report those matters, of which I have knowledge or of which I have been made aware, that might adversely affect the validity of my opinion.

6 Where, in my view, there is a range of reasonable opinion, I have indicated the extent of that range in the report and given reasons for my own opinion.
7 I have indicated the sources of all information I have used.

8 I have not, without forming an independent view, included or excluded anything which has been suggested to me by others (in particular my instructing lawyers).

9 At the time of signing the report I consider that it is complete and accurate. I will notify those instructing me if, for any reason, I subsequently consider that the report requires any correction or qualification or if between the date of this report and the trial there is any change in circumstances which affect my declarations at (2) above.

10 I understand that:

(a) my report, subject to any corrections before swearing as to its correctness, will form the evidence to be given under oath;

(b) I may be cross-examined on the report by a cross-examiner assisted by an expert;

(c) I am likely to be the subject of public adverse criticism by the judge if the court concludes that I have not taken reasonable care in trying to meet the standards set out above.

11 This report is provided to those instructing me with the sole purpose of assisting the court in this particular case. It may not be used for any other purpose, nor may it be disclosed to any third party, other than the National Probation Service, without my express written authority.

12 This report has been prepared in accordance with the Rule 33 of the Criminal Procedure Rules. 
The requirement for a declaration of truth that is the same as that in a witness statement (Rule 33.3(1) (j)), but not the same as that required in reports in civil cases, can be satisfied by ending the report with a statement as set out in Box 3 .

\section{Pre-hearing discussions}

The provision for a pre-hearing discussion between experts (Rule 33.5) will again be familiar to psychiatrists who have prepared reports in civil or family proceedings. Failure to cooperate may result in the instructing party being prevented from relying on the psychiatric report (Rule 33.6).

\section{Single joint experts}

It was anticipated that the power to direct the appointment of a single joint expert might be contentious (Rules 33.7, 33.8). It is likely to be an infrequently used power and it is uncertain to what extent it will be employed when the issues are psychiatric ones.

\section{Additional guidance}

\section{$R$ v. Bowman}

Judgment in the Court of Appeal case of $R v$. Bowman [2006] was given after the drafting of Part 33 of the Criminal Procedure Rules, but what are described in the judgment as 'necessary inclusions in an expert report' go further than the Rules themselves. The Court set out these extra requirements (Box 4) because 'some of the experts expressed to the court for the first time opinions that had not featured in their reports' and because there was a 'failure to refer to the instructions given and material provided before the reports were written'. The Court also made it clear that these requirements apply to supplemental reports.

\section{Disclosure of evidence}

The booklet Disclosure: Experts' Evidence and Unused Material (Crown Prosecution Service, 2006) particularly relates to disclosure of evidence and it is aimed at expert witnesses instructed by the prosecution team (i.e. the police and Crown Prosecution Service). It is written mainly with pathologists and forensic physicians in mind. However, its recommended key actions of 'retain, record and reveal' are of wider interest and application.

\section{Retain}

The expert needs to retain all documents and materials acquired in the course of the preparation of an expert

\section{Box 3 Statement of truth}

The contents of this report (consisting of $x$ pages signed by me) are true to the best of my knowledge and belief and I make it knowing that if it is tendered in evidence, I shall be liable to prosecution if I have willfully stated anything in it which I know to be false or do not believe to be true.

report. This includes handwritten consultation notes without which an expert witness can be embarrassed if unable to substantiate a particular statement or observation. It is desirable to retain copies of original documents before returning them, in order to deal subsequently with questions or discuss points in original case records that are not directly quoted in the report. It is also important to retain all of the papers in a case for a sufficient period after its conclusion. In a criminal case, this should be at least the period during which a convicted person can appeal. This is determined by the ranking of the court and the nature of the offence (Table 1). In any case, whether criminal or civil, the best guide is the period of time during which an action for negligence can be brought against the solicitors or counsel who have acted in the case, and this is 6 years. Alternatively, experts would be wise to retain records for as long after the conclusion of the case as the General Medical Council (GMC) would be likely to investigate a complaint against them.

Box 4 Additional requirements in an expert report for criminal proceedings

- Any limitations on the expertise

- A statement setting out the questions on which an opinion is sought

- The materials provided and considered, and the documents, statements, evidence, information or assumptions material to the opinions or on which opinions are based

- Any material facts or matters that detract from the expert's opinions

- Any points that should fairly be made against any opinions

- Extracts of literature or any other material that might assist the court

- An acknowledgment that the expert will inform all parties and, where appropriate, the court in the event of a change of opinion on material issues 
Table 1 Retention requirements for records in criminal cases

Case

Duration of

Homicide, riot, Official Secrets record retention ${ }^{1}$

Acts, treason and other offences 20 years against the State; terrorist offences; schedule 1 offenders; kidnapping; all cases in which a sentence of life imprisonment has been imposed

Other criminal cases tried on indictment

10 years

All other criminal cases

1 year

1. From the date on which the court or tribunal finally disposed of the case.

\section{Record}

The psychiatrist should record carefully the whole of the history taken from, and the examination of, the subject of the report. Such notes should be structured, clear, legible and comprehensive so that, if necessary, they can be studied by another psychiatric expert to see why and how certain opinions have been reached.

\section{Reveal}

The expert should be prepared to reveal everything in the report. However, if it seems advisable or necessary to exclude any material, explicit reference should be made to this so that the parties or the court can decide whether or not they should see it, although it may not be revealed in open court.

\section{Self-certification}

The Disclosure booklet goes further than other guidance for expert witnesses in requiring the expert to complete a self-certificate answering 'yes' or 'no' to various questions (Box 5) and also requiring a special declaration (Box 6). The self-certification questions indicate the sort of matters that might be raised in cross-examination in order to discredit an expert witness.

\section{Royal College of Psychiatrists: Scoping Group on Court Work}

In 2004 the College established a Scoping Group concerned with the responsibilities of psychiatric experts. The report of the Group has now been published (Royal College of Psychiatrists, 2008). It sets out a number of actions to be taken by psychiatrists. All psychiatrists who may, or do, provide expert reports will need to read this report.

\section{Box 5 Self-certification}

Expert witnesses instructed by the prosecution team in criminal cases must answer the following questions in a self-certificate annexed to their reports

- Have you ever been convicted of, cautioned for, or received a penalty notice for any criminal offence (other then minor traffic offences)?

- Are there any proceedings pending against you in any criminal or civil court?

- Are you aware of any adverse finding by a judge, magistrate or coroner about your professional competence or credibility as a witness?

- Have you ever been the subject of any adverse findings by a professional or regulatory body?

- Are there any proceedings, referrals or investigations pending against you that have been brought by a professional or regulatory body?

- Are you aware of any other information that you think may adversely affect your professional competence and credibility as an expert witness?

\section{Box 6 Crown Prosecution Service declara- tion}

I am an expert in psychiatry and I have been requested to provide a statement. I confirm that I have read guidance contained in a booklet known as Disclosure: Expert's Evidence and Unused Material, which details my role and documents my responsibilities, in relation to revelation as an expert witness. I have followed the guidance and recognise the continuing nature of my responsibilities of revelation. In accordance with my duties of revelation, as documented in the guidance booklet,

(a) I confirm that I have complied with my duties to record, retain and reveal material in accordance with the Criminal Procedure and Investigations Act 1996, as amended;

(b) I have (not) compiled an Index of all material (as I have no unused material in my possession). I will ensure that the Index is updated/prepared in the event I am provided with or generate additional material;

(c) in the event my opinion changes on any material issue, I will inform the investigating officer, as soon as reasonably practicable and give reasons.

Signed

Dated 
TheScoping Group goes further than other guidance with regard to the need for a more transparent process of gaining consent for the psychiatric assessment from the subject of an expert report and advises the use of a written consent to document that it calls 'valid' or 'express' consent. It calls for each College faculty to develop a pro forma addressing consent and confidentiality in relation to legal proceedings and to devise a model consent form. Amodel consent form that I have devised for use in adult cases is available from my website (www.drkeithrix.co.uk). The Group advises psychiatrists to write their reports in a form that is recognised as standard for their area of expertise and that is helpful to those who have commissioned the report and to the court.

\section{A passing cloud?}

Adverse publicity, not all justified, has threatened the reputation of the expert witness. As in any walk of life, there will always be a few people who have the potential to damage the reputation of the majority. Psychiatrists have unfortunately been among those whose actions as experts have had this effect. Careful observance of the panoply of rules, guidance and protocols, along with a commitment to continuing professional development, will enable psychiatrists to enhance the standing of medical experts in general, protect themselves in the event of complaint and enable them to assist courts and tribunals where justice is delivered and disputes are resolved. As Dame Elizabeth Butler-Sloss said, 'Expert medical witnesses are a crucial resource. Without them we [the judges] could not do our job' (Butler-Sloss \& Hall, 2002).

\section{Declaration of interest}

None.

\section{References}

Butler-Sloss, E. \& Hall, A. (2002) Expert witnesses, courts and the law. Journal of the Royal Society of Medicine, 95, 431-434.

Crown Prosecution Service (2006) Disclosure: Experts' Evidence and Unused Material. Guidance Booklet for Experts (Annex K). TSO (The Stationery Office) (http:/ / www.cps.gov.uk/legal/ section20/chapter_a annex_k.html\#02).

Department of Constitutional Affairs (2006) Criminal Procedure Rules. Part 33. Expert Evidence. TSO (The Stationery Office) (http://www.justice.gov.uk/criminal/procrules_fin/ contents/rules/part_33.htm).

Rix, K. J. B. (1999) Expert evidence and the courts. 1. The history of expert evidence. Advances in Psychiatric Treatment, 5, 71-77.

Rix, K. J. B. (2000) The new Civil Procedure Rules: 2. Part 35 provisions and their implications. Advances in Psychiatric Treatment, 6, 219-225.

Rix, K. J. B. (2008) The psychiatrist as expert witness. Part 1: general principles and civil cases. Advances in Psychiatric Treatment, 14, 37-41.

Royal College of Psychiatrists (2008) Court Work. Final Report of a Scoping Group (College Report CR147). Royal College of Psychiatrists.

$R$ v. Bowman [2006] EWCA Crim 417.

\section{MCQs}

1 In criminal cases:

a the overriding objective is that cases should be dealt with expeditiously

b the psychiatric expert can refer only to facts within their own knowledge

c the psychiatric expert need not identify points which can fairly be made against the opinions expressed

d single joint experts are likely to be used frequently

e expert reports should include a biographical section setting out the author's qualifications, relevant experience and accreditation.

\section{Psychiatric reports in criminal cases:}

a require the same declaration of truth as a report in a civil case

b are to be prepared by experts from a list drawn up by the Royal College of Psychiatrists

c need not state the questions on which an opinion is sought, as readers can be assumed to understand what the issues are from the opinion expressed

d should not include extracts of literature

e require an acknowledgement that the psychiatrist will inform all parties, and if appropriate the court, in the event of a change of opinion on material issues.

3 Psychiatrists reporting in criminal cases:

a involving homicide should retain their records for 30 years after the court disposed of the case

$b$ tried summarily should retain their records for 5 years after the date on which the court disposed of the case

c under the instruction of the Crown Prosecution Service should include a list of their own criminal convictions

d are not liable to prosecution if they state in a report something that they do not believe to be true

e do not have to be informed if their report is served on another party or the court.

4 The Criminal Procedure Rules relating to expert evidence:

a have been modelled on the Civil Procedure Rules

$b$ introduce the option of including a summary of the conclusions reached

c make optional a statement that the expert understands his duty to the court

d do not apply to reports prepared for the purpose of sentencing

e do not require the court's permission for reference to be made to the content of a pre-hearing discussion of expert evidence.

\begin{tabular}{|c|c|c|c|}
\hline \multicolumn{4}{|c|}{ MCQ answers } \\
\hline 1 & 2 & 3 & 4 \\
\hline a F & a $F$ & a $F$ & a $\mathrm{T}$ \\
\hline b F & b F & b F & b F \\
\hline c F & c F & c $\mathrm{T}$ & C F \\
\hline d F & d F & d F & d F \\
\hline e $\mathrm{T}$ & e $\mathrm{T}$ & e F & e $F$ \\
\hline
\end{tabular}

